\title{
1
}

\section{The Constitution of 'Choice': Voluntary Assisted Dying in the Australian State of Victoria}

\author{
Courtney Hempton ${ }^{1}$
}

\begin{abstract}
The Voluntary Assisted Dying Act (2017) provides a safe legal framework for people who are suffering and dying to choose the manner and timing of their death. ${ }^{2}$
\end{abstract}

\section{Introduction}

On 19 June 2019 the Voluntary Assisted Dying Act 2017 (Vic) came into effect, making Victoria the first state in Australia to establish a regime of physician-assisted death. ${ }^{3}$ As summarised by the state's Department of Health and Human Services, the enacted model of 'voluntary assisted dying' 'provides a safe legal framework for people who are suffering and dying to

\footnotetext{
1 PhD Candidate, Monash Bioethics Centre, Monash University; courtney.hempton@monash. edu; orcid.org/0000-0001-9444-1170. This research was supported by an Australian Government Research Training Program (RTP) Scholarship. Information in this chapter is up to date as of November 2020.

2 Department of Health and Human Services, Government of Victoria, 'Voluntary Assisted Dying: Overview', health.vic (Web Page) <https://www.health.vic.gov.au/patient-care/overview>.

3 A brief note on terminology: I use the term 'voluntary assisted dying' to refer to the specific practice regulated in Victoria, though use the more generic term 'physician-assisted death' to refer more broadly to the practice of medical assistance to die, as variously conceived in different jurisdictions.
} 
choose the manner and timing of their death'. ${ }^{4}$ Such rhetoric of 'choice' is pivotal to the state's establishment and ongoing management of voluntary assisted dying. Notably, the historically significant law reform emerged from a state parliamentary Inquiry into End of Life Choices that focused broadly on 'the need for laws in Victoria to allow citizens to make informed decisions regarding their own end of life choices' practices currently being utilised within the medical community to assist a person to exercise their preferences for the way they want to manage their end of life ${ }^{6}{ }^{6}$ Voluntary assisted dying thus emerges from a presupposition that 'end of life' may be medically managed through individual patient choice. As such, the emergence and formulation of voluntary assisted dying provokes consideration of the necessary and interrelated conditions permitting (and prohibiting) 'choice' in relation to voluntary assisted dying.

In this chapter, I critically examine the ways in which the state's distinct regulation of voluntary assisted dying constitutes and operationalises the concept of 'choice'. The state government's move to introduce voluntary assisted dying emerged from the recommendations of the aforementioned inter-party parliamentary Inquiry into End of Life Choices, ${ }^{7}$ and an ensuing Ministerial Advisory Panel on Voluntary Assisted Dying; ${ }^{8}$ the enacted Voluntary Assisted Dying Act 2017 (Vic) is the cumulative product of these processes. A close reading of both the legislation and reports produced throughout the law reform process offer critical insight into the conception and operationalisation of voluntary assisted dying as a new 'end of life choice'. Despite the rhetoric of choice evident in the state's justification for establishing voluntary assisted dying, I contend there are pivotal ways in which the conditions created for 'choice' in relation to voluntary assisted dying are delimited, and markedly inconsistent with the

\footnotetext{
$4 \quad$ 'Voluntary Assisted Dying: Overview' (n 2) (emphasis added).

5 Standing Committee on Legal and Social Issues, Parliament of Victoria Legislative Council, Inquiry into End of Life Choices (Final Report, June 2016) xiii (emphasis added).

6 Ibid xiii (emphasis added).

7 See generally Standing Committee on Legal and Social Issues, Parliament of Victoria Legislative Council, 'Community Views Sought on Choices for End of Life' (Media Release, 28 May 2015); Standing Committee on Legal and Social Issues, Parliament of Victoria Legislative Council, Inquiry into End of Life Choices (Interim Report, November 2015); End of Life Choices (Final Report) (n 5).

8 See generally Department of Health and Human Services, Government of Victoria, Voluntary Assisted Dying Bill (Discussion Paper, January 2017); Department of Health and Human Services, Government of Victoria, Voluntary Assisted Dying Bill: Consultation Overview (Interim Report, May 2017); Department of Health and Human Services, Government of Victoria, Ministerial Advisory Panel on Voluntary Assisted Dying (Final Report, July 2017); Margaret M O'Connor et al, 'Documenting the Process of Developing the Victorian Voluntary Assisted Dying Legislation' (2018) 42(6) Australian Health Review 621.
} 
state's broader regulatory approach to medical care and decision-making. To demonstrate this claim, I will interrogate the state's constitution of 'choice' as evident in the Act, and briefly trace the emergence of consequential provisions through the law reform process, considered in terms of 'patient choices', and the interconnection with 'practitioner choices'. The aim of this chapter is not to analyse the state's rationale for establishing its particular regime of voluntary assisted dying, ${ }^{9}$ nor to examine clinical implementation. Rather, I aim to demonstrate some of the distinct ways in which 'choice' in relation to voluntary assisted dying is produced - the state's institution of voluntary assisted dying in Victoria demarcates and deploys the concept of choice in unprecedented and anomalous ways. I will attend to the operationalisation of choice in voluntary assisted dying in the following sections, though first will overview the conceptualisation of voluntary assisted dying across stages of the law reform process, as conceived in relation to the notion of 'choice'.

\section{'End of life choices': The conception of voluntary assisted dying}

Victoria is the first state in Australia to develop and permit the practice of 'voluntary assisted dying..$^{10}$ In essence, voluntary assisted dying refers to 'assistance to die provided in medical context'. ${ }^{11}$ As specifically defined in the Voluntary Assisted Dying Act 2017 (Vic) (hereafter 'the Act'), the term

9 For critical analysis of the state's rationale for voluntary assisted dying, see Marc Trabsky's chapter in this collection, 'The Neoliberal Rationality of Voluntary Assisted Dying'; see also John Keown, "Voluntary Assisted Dying" in Australia: The Victorian Parliamentary Committee’s Tenuous Case for Legalization' (2018) 33(1) Issues in Law \& Medicine 55.

10 At the time of writing, other jurisdictions in Australia are actively considering the issue of 'end of life choices' including physician-assisted death. Most substantially in Western Australia, the Voluntary Assisted Dying Act 2019 (WA) - legislation similar in nature to the Victorian legislation passed on 10 December 2019, and will come into effect in mid-2021 after an approximate 18-month implementation period. The Western Australian legislation was introduced following a similar law reform process to Victoria; an initial inquiry into 'end of life choices', and consequent Ministerial Expert Panel on Voluntary Assisted Dying: see especially Joint Select Committee on End of Life Choices, Parliament of Western Australia, My Life, My Choice: The Report of the Joint Select Committee On End OfLife Choices (Report No 1, August 2018); Department of Health, Government of Western Australia, Ministerial Expert Panel on Voluntary Assisted Dying (Final Report, June 2019). Similar inquiries into 'end of life choices' are in progress in other states and territories (noting Australian territories are currently prohibited in effect by the federal Euthanasia Laws Act 1997 (Cth) from permitting 'euthanasia'). For a history of law reform attempts across Australia see also Lindy Willmott, Ben White, Christopher Stackpoole et al, '(Failed) Voluntary Euthanasia Law Reform in Australia: Two Decades of Trends, Models and Politics' (2016) 39(1) University of New South Wales Law Journal 1.

11 End of Life Choices (Final Report) (n 5) 14. 
voluntary assisted dying refers to 'the administration of a voluntary assisted dying substance', ${ }^{12}$ 'for the purpose of causing a person's death'. ${ }^{13}$ In effect, the state has established a particular regime of 'physician-assisted death' that provides primarily for the practice of patient 'self-administration' of a prescribed lethal substance; ${ }^{14}$ in circumstances in which a patient is physically unable to self-administer, 'practitioner administration' is permitted, which allows a relevantly qualified and specifically trained medical practitioner to directly administer the substance to the patient. ${ }^{15}$ The Act delineates the necessary conditions for access to voluntary assisted dying as an intentional life-ending option, and makes explicit the ways in which the practice will be governed as part of regulated medical care.

The broad framework of the state's voluntary assisted dying regime was outlined by the inter-party Victorian Legislative Council Legal and Social Issues Committee (Legislation and References) (hereafter the 'Committee'), which conducted the Inquiry into End of Life Choices (hereafter the 'Inquiry'), and later refined by the state-appointed Ministerial Advisory Panel on Voluntary Assisted Dying (hereafter the 'Panel'), which developed the Voluntary Assisted Dying Bill 2016 (Vic). ${ }^{16}$ Alongside recommendations to improve aspects of palliative care and advance care planning, ${ }^{17}$ the Committee's final recommendation 'recommendation 49' - was that the state should introduce voluntary assisted dying: ${ }^{18}$ specifically, that the state

should introduce legislation to allow adults with decision making capacity, suffering from a serious and incurable condition who are at the end of life to be provided assistance to die in certain circumstances. ${ }^{19}$

The eventually adopted legislation emanates in essence from the 'assisted dying framework' proposed by the Committee, ${ }^{20}$ though a number of consequential changes were introduced by the Panel, and amendments

12 Voluntary Assisted Dying Act 2017 (Vic) s 3.1 (definition of 'voluntary assisted dying').

13 Ibid s 3.1 (definition of 'voluntary assisted dying substance').

14 Ibid $s 47$.

15 Ibid s 48.

16 Courtney Hempton and Catherine Mills, 'Constitution of "the Already Dying": The Emergence of Voluntary Assisted Dying in Victoria' (2021) 18(2) Journal of Bioethical Inquiry 265 doi.org/ 10.1007/s11673-021-10107-1.

17 End of Life Choices (Final Report) (n 5) xxix-xxxiv.

18 Ibid xxxiv.

19 Ibid 237.

20 Ibid 210-36. 
further passed during parliamentary debate. While a complete history of the development of the state's model of voluntary assisted dying is beyond the scope of the current chapter, the rendering of 'choice' in the formulation of the voluntary assisted dying legislation is instrumental.

During the initial Inquiry stage of the law reform process, the Committee sought 'community views on the need for laws to allow people broader scope in their end of life choices'. ${ }^{21}$ While the Inquiry addressed 'end of life' broadly, much attention was devoted to whether or not some form of lawful physician-assisted death ought to be introduced. The ensuing discourse predominantly followed familiar 'for' and 'against' arguments seen in the broader and ongoing debate ${ }^{22}$ - arguments utilised by the those advocating for the introduction of physician-assisted death focused predominantly on the notion of patient choice. ${ }^{23}$ Though in terms of the composition of 'choice' in relation to physician-assisted death, little definitional clarity was offered throughout the law reform process to distinguish between the meanings of various nebulous concepts and terms pertaining to patient choice; discourse concerning aspects of autonomy, control, decision-making, options and self-determination. For example, the Committee undertook a thematic analysis of arguments offered in public submissions ${ }^{24}$ to the Inquiry arguing in support of (some form of) lawful voluntary assisted dying. The Committee's analysis provides an indication of community sentiment regarding the notion of choice in relation to voluntary assisted dying. Notably 'choice' is identified as the most dominant theme in arguments supporting voluntary assisted dying, and notions of choice also feature across a number of other themes identified by the Committee. ${ }^{25}$ The primary analytic theme titled 'choice' is described by the Committee as:

21 'Community Views Sought on Choices for End of Life' (n 7).

22 End of Life Choices (Final Report) (n 5) 303-13. See generally Gerald Dworkin, RG Frey and Sissela Bok, Euthanasia and Physician-Assisted Suicide: For and Against (Cambridge University Press, 1998); Dieter Birnbacher and Edgar Dahl (eds), Giving Death a Helping Hand-Physician-Assisted Suicide and Public Policy: An International Perspective (Springer, 2008).

23 End of Life Choices (Final Report) (n 5) 296.

24 The Committee received a total 1,037 submissions throughout the course of the Inquiry, receiving 925 submissions from individuals and 112 from organisations. As advised by the Committee, only 1,023 submissions are included in its content analyses, as 14 were received too late for inclusion: Ibid 295.

25 Ibid 296-7. 
The manner of a person's death should be completely up to that person. Each person should be able to choose how they die, just as they choose how they live. As such, assisted dying should be legalised. ${ }^{26}$

The theme of 'control' is also relevant to voluntary assisted dying as an option or choice, described by the Committee as: 'Having the option of assisted dying would give dying people a feeling of control over their death, and remaining life. ${ }^{27} \mathrm{~A}$ further theme that explicitly mentions choice, though analytically separated from the principle theme of choice, is that the 'state should not prevent', described as:

The state should not create laws that prevent people being able to choose when and how they die in the context of irremediable suffering. Doctors should be free from legal liability to provide assisted dying. ${ }^{28}$

Similarly, the theme 'others' morals should not prevent' reflects ideas of noninterference in personal choice and decision-making:

The morals, religion, and ethics of other people should not affect a personal decision about ending your own life when experiencing irremediable suffering. The law on assisted dying should reflect this. ${ }^{29}$

Further, the theme 'legal options inhumane' reflects the idea of choice in relation to existing options, described as:

The current options for hastening death, which include the patient refusing treatment, food and water, are inhumane. They subject patients to unnecessary pain and suffering that could be avoided by assisted dying. ${ }^{30}$

The Committee also offered a synopsis of the recurring arguments encountered throughout the Inquiry, drawing on written submissions received, oral testimony from witnesses and broader academic research. The Committee notes 'autonomy' is a common argument in favour of establishing lawful voluntary assisted dying. In describing the general

26 Ibid 297 (emphasis added).

27 Ibid 297 (emphasis added).

28 Ibid 297 (emphasis added).

29 Ibid 297 (emphasis added).

30 Ibid 297 (emphasis added). 
content of autonomy-based arguments, the Committee notes 'submissions to the Inquiry that included the autonomy argument often used the word "choice", but sometimes also referred to "control". ${ }^{31}$

It is somewhat unclear how the Committee interpreted or weighted various arguments pertaining to the concept of 'choice' in moving to recommend the state establish lawful (voluntary) assisted dying as a new 'end of life' option, and more specifically to prescribe its particular 'assisted dying framework'. However, the Committee's general approach to 'end of life care' - in terms of which voluntary assisted dying is rendered - is most clearly articulated through the Committee's stated 'Core Values for End of Life Care' (hereafter 'Core Values'). The Core Values are described by the Committee as 'a set of shared core values for end of life care ... [to] provide an understanding of the beliefs that underpin the Committee's approach to this subject'; $; 2$ the twelve 'beliefs' were developed by the Committee based on learnings throughout the Inquiry process. ${ }^{33} \mathrm{~A}$ number of the Core Values and their descriptions reflect notions related to 'choice', including beliefs regarding promoting open discussion about mortality and planning for dying and death, self-determination, informed choices at the end-of-life, person-centred care and equitable access to end-of-life 'options', in terms of availability of high-quality care across geographic locations and preferred setting. ${ }^{34}$ With regard to these Core Values, the Committee determined its model of lawful voluntary assisted dying reflected and aligned with the legal and medical values and culture that are essential to Victorians'. ${ }^{35}$

While the Committee's model of 'assisted dying' provided the foundation for the state's approach to voluntary assisted dying, the regime was then refined in accord with recommendations made by the Panel. ${ }^{36}$ In regard to conceptualising voluntary assisted dying in terms of 'choice', the Panel highlighted 'clear and consistent themes [that] have emerged about what matters to Victorians for their care at the end-of-life, ${ }^{37}$ including 'placing people at the centre of decision making about their own medical

\footnotetext{
31 Ibid 306.

32 Ibid 15.

33 Ibid 15.

34 Ibid 16.

35 Ibid 21.

36 See generally 'Voluntary Assisted Dying Bill' (Discussion Paper) (n 8); Voluntary Assisted Dying Bill: Consultation Overview (Interim Report) (n 8); Ministerial Advisory Panel on Voluntary Assisted Dying (Final Report) (n 8); O'Connor et al (n 8).

37 Ministerial Advisory Panel on Voluntary Assisted Dying (Final Report) (n 8) 34.
} 
treatments', and 'genuine choice that responds to people's needs' ${ }^{38}$ Adapting the Committee's twelve 'Core Values', the Panel offered nine 'Guiding Principles' that underpin its recommendations. ${ }^{39}$ In terms of choice, key 'Guiding Principles' include notions of 'respecting autonomy', 'informed decision-making' and 'genuine choice'. As demarcated by the Panel, 'respecting autonomy' means 'providing people with a degree of control over the timing and manner of death', ${ }^{40}$ but 'does not mean allowing people to do whatever they want'. ${ }^{41}$ 'Informed decision-making' entails being supported to make well-informed decisions; 'if a person is not properly informed, their decision will not necessarily reflect their will'42 - it is critical that a person has all the necessary information available to them to identify the option that is the most consistent with their preferences and values. ${ }^{43}$ In terms of 'genuine choice', the Panel determined that voluntary assisted dying should only be an option for people 'who have a range of treatment options available to them ... [it] cannot be an alternative to palliative care or being offered the best available treatment'. ${ }^{44}$ As recommended by the Panel, its list of 'Guiding Principles' appear as 'Principles' in the Act, to guide interpretation of duties in relation to voluntary assisted dying. ${ }^{45}$ Key Principles in relation to 'choice' featured in the Act include 'a person's autonomy should be respected', ${ }^{46}$ 'a person has the right to be supported in making informed decisions about the person's medical treatment ${ }^{37}$ and individuals are entitled to genuine choices regarding their treatment and care'. ${ }^{48}$ As summarised by Rosalind McDougall and Bridget Pratt, a number of the Principles listed in the Act contribute to fostering 'a normative environment that supports individual choice in relation to [voluntary assisted dying]' ${ }^{49}$

38 Ibid 34.

39 Ibid 43-6.

40 Ibid 44.

41 Ibid 44.

42 Ibid 44.

43 Ibid 44.

44 Ibid 44.

45 Voluntary Assisted Dying Act 2017 (Vic) s 5.

46 Ibid s 5(1)(b).

47 Ibid s 5(1)(c).

48 Ibid s 5(1)(h).

49 Rosalind McDougall and Bridget Pratt, 'Too Much Safety? Safeguards and Equal Access in the Context of Voluntary Assisted Dying Legislation' (2020) 21(1) BMC Medical Ethics 38, 8. 


\section{Voluntary assisted dying: Patient 'choices'}

While a discourse of individual patient choice is drawn on to justify the state's institution of lawful voluntary assisted dying, the concept of choice is operationalised in distinct ways. Emerging from the state's law reform process, the Act in effect delineates the necessary conditions for access to voluntary assisted dying as an intentional life-ending medical option, and makes explicit a series of necessary and interrelated conditions permitting (and prohibiting) patient 'choice' in relation to voluntary assisted dying.

Foremost, the Act functions to distinguish between those deemed eligible (and ineligible) for voluntary assisted dying. Primarily, in formulating voluntary assisted dying exclusively for those medically prognosed to die 'within weeks or months', ${ }^{50}$ elsewhere Catherine Mills and I contend the state constructs the bounds of a medico-legal category, which we term 'the already dying'; ${ }^{51}$ the category of the already dying is constituted through the interrelated (in)eligibility criteria specified in the Act. In effect, we contend this category of 'the already dying' functions to distinguish between lives the state deems terminable - those eligible for voluntary assisted dying, described by the state as those who are already dying from an incurable, advanced and progressive disease, illness or medical condition $^{52}$ - and lives that are not. ${ }^{53}$ I contend the most significant way in which the state constitutes choice in relation to voluntary assisted dying is rendered in terms of 'the already dying'. As summarised by the Committee, voluntary assisted dying 'should provide an option that can limit suffering at the very end of life, not a way to end life for those who are otherwise not dying.${ }^{54}$ As such, the category of the already dying functions to frame choice in a particular way:

The recommended eligibility criteria ensure voluntary assisted dying will allow a small number of people, at the end of their lives, to choose the timing and manner of their death. There is no intention to give people who are not dying access, and the legislation will not give these people an option to choose between living and dying. ${ }^{55}$

50 Voluntary Assisted Dying Act 2017 (Vic) s 9(1)(d)(iii).

51 I provide a detailed argument regarding the constitution of 'the already dying' in Hempton and Mills (n 16).

52 'Voluntary Assisted Dying: Overview' (n 2) (emphasis added).

53 Hempton and Mills (n 16).

54 End of Life Choices (Final Report) (n 5) 224 (emphasis added).

55 Ministerial Advisory Panel on Voluntary Assisted Dying (Final Report) (n 8) 13 (emphasis added). 
In this sense, the choice created by voluntary assisted dying is rendered as a choice that is not between 'living and dying' per se - not a choice between 'life' and 'death' - but rather an option for those already dying to 'choose the manner and timing of their death'. As recapitulated by the Panel, 'voluntary assisted dying would not give people the option to choose to live or die, as they must already be at the end of their life. ${ }^{56}$ In terms of choice then, the exclusive category of the already dying serves to prohibit choice for the corollary non-dying. The category of the already dying functions to 'safeguard' those 'people who are not dying' from being able to choose the manner and timing of death, while enabling 'only those who are already dying ${ }^{57}$ to choose death. ${ }^{58}$

One of the other instrumental ways in which the concept of choice is constituted is through a distinct interpretation of medico-legal 'voluntariness'. Indeed, the original term adopted by the Committee 'assisted dying' - was explicitly amended by the Panel to include the word voluntary; as determined by the Panel, the revised term 'voluntary assisted dying' 'puts the focus on the term "voluntary" as an emphatic statement that this is a decision initiated by a person who is suffering and takes responsibility for the decision' ${ }^{59}$ In this sense, voluntary assisted dying - by means of the necessary 'voluntariness' - is cast in relation to a decision, or choice, and in terms of 'responsibilisation'; the individual patient voluntarily making the decision is deemed solely responsible for the choice. Notably, the state's selected terminology, and 'emphatic' allocation of patient responsibility for voluntary assisted dying, obscures the necessary involvement of the medical discipline and professional responsibilities of individual medical practitioners involved in providing the patient with assistance to die. Not only does the term 'voluntary assisted dying' veil the medical aid or assistance inherent in voluntary assisted dying - the requisite action of physicianassisted death is indeed 'assistance' - the emphasis on patient responsibility further fails to account for the significant role of medical practitioners as gatekeepers to access voluntary assisted dying; a patient is not able to access or 'choose' voluntary assisted dying without the substantial involvement of medical practitioners. ${ }^{60}$

56 Ibid 44 (emphasis added).

57 'Voluntary Assisted Dying: Overview' (n 2) (emphasis added).

58 Hempton and Mills (n 16).

59 Ministerial Advisory Panel on Voluntary Assisted Dying (Final Report) (n 8) 8 (emphasis added).

60 Voluntary Assisted Dying Act 2017 (Vic) s 6. 
Relatedly, 'voluntariness' is demarcated in relation to 'decision-making capacity', such that to be eligible for voluntary assisted dying a 'person must have decision-making capacity in relation to voluntary assisted dying. ${ }^{61}$ Decision-making capacity is generally defined in the state's Medical Treatment Planning and Decisions Act 2016 (Vic) in decisionrelative terms, ${ }^{62}$ such that:

A person has decision-making capacity in relation to voluntary assisted dying if the person is able to-

a. understand the information relevant to the decision relating to access to voluntary assisted dying and the effect of the decision; and

b. retain that information to the extent necessary to make the decision; and

c. use or weigh that information as part of the process of making the decision; and

d. communicate the decision and the person's views and needs as to the decision in some way, including by speech, gestures or other means. ${ }^{63}$

In this sense, the concept of 'choice' - or the ability to choose - is medically assessed in terms of a patient's cognitive capacity in relation to deciding to 'manage their end of life' with voluntary assisted dying. ${ }^{64}$ While a decision-relative account of decision-making capacity is in accord with the state's contemporary approach to legislatively regulating medical treatment decision-making, ${ }^{65}$ the state's prohibition of requesting voluntary assisted dying through an advance care directive is inconsistent with other medical treatment and care decisions, including other 'end of life' (and in consequence life-ending) choices. In outlining the 'assisted dying framework' the Committee stated it 'does not support access to [voluntary] assisted dying through any kind of advance care directive'. ${ }^{66}$

61 Ibids $9(1)$ (c).

62 See generally Courtney Hempton and Neera Bhatia, 'Deciding for When You Can't Decide: The Medical Treatment Planning and Decisions Act 2016 (Vic)' (2020) 17(1) Journal of Bioethical Inquiry 109.

63 Voluntary Assisted Dying Act 2017 (Vic) ss 4(1)(a)-4(1)(d).

64 I provide a more detailed overview of what we term the 'cognitive elements' of voluntary assisted dying (in)eligibility, including 'voluntariness' and decision-making capacity in Hempton and Mills (n 16); for a discussion regarding the clinical assessment of decision-making capacity in the context of voluntary assisted dying see Carmelle Peisah, Linda Sheahan and Ben White, 'The Biggest Decision of Them All-Death and Assisted Dying: Capacity Assessments and Undue Influence Screening' (2019) 49(6) Internal Medicine Journal 792.

65 Hempton and Bhatia (n 62).

66 End of Life Choices (Final Report) (n 5) 221. 
The Committee's position was maintained by the Panel, which determined that 'requiring a person to have decision-making capacity throughout the voluntary assisted dying process represents an important safeguard to protect against abuse'. ${ }^{67}$ The requirement to have decisionmaking capacity throughout the whole voluntary assisted dying process introduces a temporal condition for decision-making capacity in relation to voluntary assisted dying that is not necessitated for other medical decisions in Victoria, which are able to be effected in circumstances in which a patient does not have decision-making capacity, via an advance care directive or a proxy 'medical treatment decision-maker' ${ }^{68}$ In effect, the standard for decision-making capacity in relation to voluntary assisted dying is emphatically more demanding than that required for other medical treatment and care decisions in Victoria.

Even for an individual who prima facie meets all of the eligibility criteria, choosing voluntary assisted dying necessitates the navigation of a complex voluntary assisted dying apparatus; a patient's choice is absolutely contingent on the - largely obscured - choices of individual medical practitioners, health services and other care institutions, and ultimately the state. As outlined, 'choice' in voluntary assisted dying necessitates being diagnosed and prognosed as 'already dying', and further clinical assessment of one's 'voluntariness' and 'decision-making capacity' in relation to voluntary assisted dying, ${ }^{69}$ in addition to a host of other (in)eligibility criteria as specified in the Act. Medical assessment of patient eligibility is then subject to approval by the state, requiring issuance of a 'voluntary assisted dying permit ${ }^{70}$ - literal permission from the state is required for a patient to choose voluntary assisted dying. Ultimately under the Victorian model of voluntary assisted dying, whether or not a particular patient is empowered to actually choose whether and when - or not - they may self-administer the voluntary assisted dying substance to cause their death (or have the substance administered by a practitioner if deemed medically necessary) is really available only once the relevant 'permit' is issued by the state, which then enables the patient to request access to

67 Ministerial Advisory Panel on Voluntary Assisted Dying (Final Report) (n 8) 8 (emphasis added).

68 For detailed discussion of the regulation of medical treatment decision-making in Victoria see Hempton and Bhatia (n 62); John Chesterman, 'Prioritising Patients' Preferences: Victoria's New Advance Planning and Medical Consent Legislation' (2017) 25(1) Journal of Law and Medicine 46.

69 For a discussion regarding the clinical assessment of decision-making capacity in the context of voluntary assisted dying, see Peisah, Sheahan and White (n 64).

70 Voluntary Assisted Dying Act 2017 (Vic) ss 3(1) (definitions of 'voluntary assisted dying permit', 'self-administration permit', 'practitioner administration permit'), 45-53, 56. 
the 'voluntary assisted dying substance', which will then be provided to the patient by the statewide pharmacy service. Rather than enabling a patient to 'choose the manner and timing of death' directly, the option that may be available to a patient is to merely make a request for voluntary assisted dying - or a request to be medically assessed for voluntary assisted dying. In terms of a patient actually being enabled to choose to die by means of voluntary assisted dying, such choice is wholly contingent on medical practitioner participation, which too is operationalised in distinct ways.

\section{Voluntary assisted dying: Practitioner 'choices'}

While the state's model of voluntary assisted dying deliberately emphasises the patient, the role of health practitioners in the management of voluntary assisted dying is inherent. In operationalising the concept of patient choice in its model of voluntary assisted dying, the state emphasises the extensive regulation of the eligibility and assessment and approval processes required for access to voluntary assisted dying, establishing medical practitioners as voluntary assisted dying gatekeepers, whether they choose to participate or not. However, the activities of health practitioners are further regulated by the state in ways peculiar to voluntary assisted dying, including the establishment of both new prohibitions and new rights for health practitioners.

A most extraordinary feature of the Victorian voluntary assisted dying legislation is its 'gag clause ${ }^{71}$ - the Act explicitly prohibits health practitioners from initiating a discussion about voluntary assisted dying with patients. As specified in the legislation, all registered health practitioners in the state are explicitly prohibited from initiating a discussion that is either in substance about voluntary assisted dying, or in substance suggests voluntary assisted dying to a patient in their care. ${ }^{72}$ The inclusion of a gag clause was recommended by the Panel as a 'safeguard', with the stated policy intention ' $[\mathrm{t}] \mathrm{o}$ ensure a person is not coerced or unduly influenced into accessing voluntary assisted dying and to demonstrate the request for voluntary assisted dying is the person's

71 Bryanna Moore, Courtney Hempton and Evie Kendal, 'Victoria’s Voluntary Assisted Dying Act: Navigating the Section 8 Gag Clause' (2020) 212(2) Medical Journal of Australia 1.

72 Voluntary Assisted Dying Act 2017(Vic) s 8. 
own voluntary decision'. ${ }^{73}$ To my knowledge at the time of writing, a gagstyle clause is not a feature of any other physician-assisted death regime - Victoria is the only jurisdiction in the world to have a gag clause in effect in relation to physician-assisted death. ${ }^{74}$ The gag clause has been critiqued on several grounds, foremost in relation to equitable access to voluntary assisted dying, and further in relation to potential issues regarding informed patient decision-making and consent. ${ }^{75}$ Along with colleagues Bryanna Moore and Evie Kendal, I elsewhere critique the state's prohibition, outlining some of the ethically problematic implications for the provision of healthcare; we conclude 'section 8 is an unwarranted infringement on communication between health practitioners and their patients' ${ }^{76}$ In terms of 'choice', the gag clause

places a burden of prior knowledge of voluntary assisted dying on patients ... [c]ertain groups may end up missing vital information that could impact their end-of-life choices, particularly those with lower levels of health literacy. ${ }^{77}$

In this sense, the gag clause, while a prohibition regulating the activities of health practitioners, has the potential to impact patient choice, in terms of (lack of) awareness of available options. As noted by Carolyn Johnston and James Cameron, a patient

will need to identify that voluntary assisted dying may be an option for them without the initial assistance of their health practitioner. This may limit access and prevent people who may be eligible for voluntary assisted dying from considering it as an option. ${ }^{78}$

73 Ministerial Advisory Panel on Voluntary Assisted Dying (Final Report) (n 8) 91.

74 The Voluntary Assisted Dying Act 2019 (WA) will come into effect in mid-2021, and features a somewhat refined gag clause, relative to the Victorian legislation - in Western Australia medical practitioners and nurse practitioners will not be subject to a gag clause, but if initiating discussion about voluntary assisted dying must at the same time also inform the person of the treatment options and the palliative care options available, and the likely outcome of those options, while all other 'health care workers' in Western Australia (including all other registered health practitioners) will be prohibited from initiating discussion about voluntary assisted dying: Voluntary Assisted Dying Act 2019 (WA) s 10.

75 See especially Moore, Hempton and Kendal (n 71); Carolyn Johnston and James Cameron, 'Discussing Voluntary Assisted Dying' (2018) 26(2) Journal of Law and Medicine 454; Lindy Willmott, Ben White, Danielle Ko et al, 'Restricting Conversations About Voluntary Assisted Dying: Implications for Clinical Practice' (2020) 10(1) BMJ Supportive \& Palliative Care 105.

76 Moore, Hempton and Kendal (n 71) 1.

77 Ibid 2.

78 Johnston and Cameron (n 75) 458. 
In this sense, voluntary assisted dying may be precluded from consideration as an end-of-life option, if perhaps patients are not aware the state now permits voluntary assisted dying, or are unaware of the state's protocol regarding patient-initiated requests for access - a patient cannot make a decision about voluntary assisted dying if they do not know voluntary assisted dying is an option available to them.

Relatedly, the gag clause highlights a further overt inconsistency between information provision regarding voluntary assisted dying, compared to other end-of-life choices, which may have implications for decisionmaking and 'informed consent'. In order to access voluntary assisted dying, as part of the clinical assessment protocol, each of the medical practitioners must inform the patient of 'the treatment options available to the person and the likely outcomes of that treatment; [and] the palliative care options available to the person and the likely outcomes of that care'. ${ }^{79}$ This protocol appears to stem from the Principles of 'genuine choice' and 'informed decision-making' as described previously; voluntary assisted dying should only be an option in the context of alternatives, including the best available treatment and palliative care. However, in distinct contrast when making any other 'end of life' medical decisions, for example about treatment or palliative care, patients are not similarly required to be informed about voluntary assisted dying as an available option - indeed, not only is there no requirement to inform patients about voluntary assisted dying as an option, the 'section 8' gag clause expressly prohibits registered health practitioners from informing patients about voluntary assisted dying, unless the patient explicitly enquires. As summarised by Lindy Willmott and colleagues, 'the concern is that the section 8 restriction will prevent some patients approaching the [end of life] from making informed decisions, ${ }^{80}$ In practice then, patients considering choosing voluntary assisted dying are legally required have alternative treatment and palliative care options explained to them, while patients considering choosing treatment or palliative care options must not have voluntary assisted dying mentioned to them, except at their explicit request. In this regard, the principles of 'genuine choice' and 'informed decision-making' are operationalised differently in regard to considering choosing voluntary assisted dying, as compared to considering other endof-life options.

79 Voluntary Assisted Dying Act 2017 (Vic) ss 19(1)(b)-19(1)(c), 28(1)(b)-(c).

80 Willmott, White, Ko et al (n 75) 4. 
Even if a patient is well-informed enough to request information about voluntary assisted dying, another way in which voluntary assisted dying is regulated differently to other medical options is through the practitioner 'conscientious objection' provision. As detailed in the Act, any registered health practitioner who has a 'conscientious objection to voluntary assisted dying has the right to refuse ${ }^{\prime 81}$ to support or participate in the practice of voluntary assisted dying in any way, including refusing to provide information about voluntary assisted dying, to participate in the assessment and permit-application process, to being involved in prescribing, dispensing, supplying or administering the voluntary assisted dying substance, and/or being present at the time of administration. ${ }^{82}$ Unlike other legislated conscientious objection provisions in the state, this new right does not confer any obligations on health practitioners in order to support patients requesting information or access to voluntary assisted dying, for example requiring referral to another health practitioner. ${ }^{83}$ In effect, the conscientious objection provision establishes more 'rights' for health practitioners than patients in regard to voluntary assisted dying - there are no new rights for patients established by the Act, while health practitioners have a new unfettered right to non-participation. In terms of 'choice', the potential impact of the conscientious objection provision, in the absence of a legislated obligation for health practitioners to provide minimal patient information or an appropriate referral, may impact the ability of patients to access information about voluntary assisted dying as a lawful option.

Further, briefly, I would be remiss not to note that the potential participation of individual health practitioners may be impacted by whether or not the health service within which they practice chooses to offer voluntary assisted dying. While the practice of voluntary assisted dying continues to evolve in Victoria, participation at an organisational level is discretionary, and there are health services and care providers that will not offer voluntary assisted dying services. For example, organisations without the necessary clinical staff or expertise may offer limited voluntary assisted dying services for logistical reasons, while faith-based institutions

81 Voluntary Assisted Dying Act 2017 (Vic) s 7 (emphasis added).

82 Ibid ss $7(\mathrm{a})-7(\mathrm{f})$.

83 Cf the Abortion Law Reform Act 2008 (Vic) features a 'conscientious objection' provision, which dictates 'obligations of registered health practitioner who has conscientious objection', including that a registered health practitioner, must 'refer the woman [sic] to another registered health practitioner in the same regulated health profession who the practitioner knows does not have a conscientious objection to abortion': Abortion Law Reform Act 2008 (Vic) s 8. 
may offer no voluntary assisted dying services for values-based reasons. ${ }^{84}$ Overall, the specified medico-legal management of voluntary assisted dying makes evident what the administration of voluntary assisted dying actually produces in terms of 'choice'; the option or ability of a patient to choose voluntary assisted dying - to choose the manner and timing of their death - is absolutely contingent on the choices of others, including the necessary participation of health services and medical practitioners, and ultimately the state.

\section{Conclusion}

The establishment of voluntary assisted dying in Victoria is a historic transformation in the state's management of 'end of life choices'. As overviewed, the practice of voluntary assisted dying is operationalised through the Voluntary Assisted Dying Act 2017 (Vic), as conceptualised through a state parliamentary Inquiry into End of Life Choices, subsequent Ministerial Advisory Panel on Voluntary Assisted Dying, and further parliamentary debate on the initially proposed Voluntary Assisted Dying Bill 2016 (Vic). Despite the rhetoric of patient choice evident in the state's justification for establishing voluntary assisted dying, in this chapter I have demonstrated some of the distinct ways in which 'choice' in relation to voluntary assisted dying is demarcated and deployed. While it is beyond the scope of this chapter to trace the state's rationale for establishing its particular regime of voluntary assisted dying, it is notable that a 'discourse of safety ${ }^{85}$ pervaded the development of voluntary assisted dying in Victoria - the model of voluntary assisted dying is claimed by the state to be the 'safest, and most conservative, in the world'. ${ }^{86}$ As such, the distinct demarcation of 'choice' in relation to voluntary assisted dying as discussed may reflect a prioritisation of safety, including 'safeguards' to protect both patients and health practitioners. ${ }^{87}$ However, as explicated

84 For a more detailed discussion of organisational-level participation in voluntary assisted dying, and the potential impact on (un)equal access in Victoria, see McDougall and Pratt (n 49).

85 McDougall and Pratt (n 49).

86 See, eg, Daniel Andrews, 'Debate of Historic Voluntary Assisted Dying Bill Starts' (Media Release, 17 October 2017) <https://www.premier.vic.gov.au/debate-historic-voluntary-assisted-dyingbill-starts>; 'Voluntary Assisted Dying: Overview' (n 2).

87 See generally Ministerial Advisory Panel on Voluntary Assisted Dying (Final Report) (n 8) 181-83, 216-28. 
by Rosalind McDougall and Bridget Pratt, ' $[\mathrm{w}]$ hile safety is of course an important value, safeguards have access consequences' ${ }^{88}$ and the coherence and effects of voluntary assisted dying 'safeguards' warrant scrutiny.

The state's management of voluntary assisted dying is complex, and access to voluntary assisted dying entails navigating a new medico-legal voluntary assisted dying apparatus, which functions to delimit choice in relation to voluntary assisted dying in a number of ways that are pointedly inconsistent with the state's broader approach to regulating decision-making in a medical context. For patients, choice in regard to voluntary assisted dying is restricted to those who meet a number of necessary conditions that are not required in other medical decisionmaking circumstances, including holding prior knowledge of voluntary assisted dying as a potential option in order to make a sufficient request for voluntary assisted dying, in addition to maintaining decision-making capacity throughout the entire voluntary assisted dying request, assessment and administration process. Interrelatedly, the management of voluntary assisted dying necessitates the 'conscientious' participation of medical and potentially other health practitioners, though their involvement is constrained by the state with an unprecedented 'gag clause', and their necessary role as the essential administrators of voluntary assisted dying is obscured in a number of ways, given the state's emphasis on 'responsibilising' the patient. Ultimately, explicit approval from medical practitioners and authorisation from the state is required to permit an individual patient to 'choose' voluntary assisted dying - without permission, voluntary assisted dying is prohibited. In effect, the state's 'safeguarding' of choice in regard to voluntary assisted dying produces and deploys distinct meanings of choice that, while formulated in a values-discourse seemingly akin to broader medical care and decision-making in Victoria, delimits choice in the context of voluntary assisted dying in unprecedented and anomalous ways. In sum, the state's new option to 'choose the manner and timing of death' constitutes both patient and practitioner choice in new ways, such that voluntary assisted dying is not like other end-of-life choices. 


\section{Acknowledgements}

A preliminary version of this chapter was discussed at an invitational symposium on 'Voluntary Assisted Dying: Law? Health? Justice?' at the University of Technology Sydney (7 February 2019), and I dearly thank hosts David Carter and Dan Fleming, and other attendees, for their thoughtful reflections, in particular Marc Trabsky for his continuing support. Parts of this chapter are drawn from my doctoral dissertation, and I extend my sincerest appreciation to my supervisors, Catherine Mills and Justin Oakley, for ongoing discussions that improved aspects of this broader work in progress. Much gratitude also to Ros McDougall and Bridget Pratt for generously sharing an advance copy of their manuscript under review, cited as published.

\section{Bibliography}

\section{A Articles/books/reports}

Birnbacher, Dieter and Edgar Dahl (eds), Giving Death a Helping Hand: PhysicianAssisted Suicide and Public Policy. An International Perspective (Springer, 2008) doi.org/10.1007/978-1-4020-6496-8

Chesterman, John, 'Prioritising Patients' Preferences: Victoria's New Advance Planning and Medical Consent Legislation' (2017) 25(1) Journal of Law and Medicine 46

Department of Health, Government of Western Australia, Ministerial Expert Panel on Voluntary Assisted Dying (Final Report, June 2019)

Department of Health and Human Services, Government of Victoria, Ministerial Advisory Panel on Voluntary Assisted Dying (Final Report, 31 July 2017)

Department of Health and Human Services, Government of Victoria, Voluntary Assisted Dying Bill: Consultation Overview (Interim Report, May 2017)

Department of Health and Human Services, Government of Victoria, Voluntary Assisted Dying Bill (Discussion Paper, January 2017)

Dworkin, Gerald, RG Frey and Sissela Bok, Euthanasia and Physician-Assisted Suicide: For and Against (Cambridge University Press, 1998) 
Hempton, Courtney and Catherine Mills, 'Constitution of "the Already Dying": The Emergence of Voluntary Assisted Dying in Victoria' (2021) 18(2) Journal of Bioethical Inquiry 265 doi.org/10.1007/s11673-021-10107-1

Hempton, Courtney and Neera Bhatia, 'Deciding for When You Can't Decide: The Medical Treatment Planning and Decisions Act 2016 (Vic)' (2020) 17(1) Journal of Bioethical Inquiry 109 doi.org/10.1007/s11673-020-09960-3

Johnston, Carolyn and James Cameron, 'Discussing Voluntary Assisted Dying' (2018) 26(2) Journal of Law and Medicine 454

Joint Select Committee on End of Life Choices, Parliament of Western Australia, My Life, My Choice: The Report of the Joint Select Committee On End Of Life Choices (Report No 1, August 2018)

Keown, John, “Voluntary Assisted Dying” in Australia: The Victorian Parliamentary Committee's Tenuous Case for Legalization' (2018) 33(1) Issues in Law \& Medicine 55

McDougall, Rosalind and Bridget Pratt, 'Too Much Safety? Safeguards and Equal Access in the Context of Voluntary Assisted Dying Legislation' (2020) 21(1) BMC Medical Ethics 38 doi.org/10.1186/s12910-020-00483-5

Moore, Bryanna, Courtney Hempton and Evie Kendal, 'Victoria's Voluntary Assisted Dying Act: Navigating the Section 8 Gag Clause' (2020) 212(2) Medical Journal of Australia 67 doi.org/10.5694/mja2.50437

O'Connor, Margaret $\mathrm{M}$ et al, 'Documenting the Process of Developing the Victorian Voluntary Assisted Dying Legislation' (2018) 42(6) Australian Health Review 621 doi.org/10.1071/AH18172

Peisah, Carmelle, Linda Sheahan and Ben P White, 'Biggest Decision of Them All - Death and Assisted Dying: Capacity Assessments and Undue Influence Screening' (2019) 49(6) Internal Medicine Journal 792 doi.org/10.1111/ imj. 14238

Standing Committee on Legal and Social Issues, Parliament of Victoria Legislative Council, Inquiry into End of Life Choices (Final Report, June 2016)

Standing Committee on Legal and Social Issues, Parliament of Victoria Legislative Council, Inquiry into End of Life Choices (Interim Report, November 2015)

Willmott, Lindy, Ben White, Christopher Stackpoole et al, '(Failed) Voluntary Euthanasia Law Reform in Australia: Two Decades of Trends, Models and Politics' (2016) 39(1) University of New South Wales Law Journal 1 
Willmott, Lindy, Ben White, Danielle Ko et al, 'Restricting Conversations About Voluntary Assisted Dying: Implications for Clinical Practice' (2020) 10(1) BMJ Supportive \& Palliative Care 105 doi.org/10.1136/bmjspcare-2019-001887

\section{B Legislation}

Abortion Law Reform Act 2008 (Vic)

Euthanasia Laws Act 1997 (Cth)

Voluntary Assisted Dying Act 2017 (Vic)

Voluntary Assisted Dying Act 2019 (WA)

\section{Other}

Andrews, Daniel, 'Debate of Historic Voluntary Assisted Dying Bill Starts' (Media Release, 17 October 2017) <https://www.premier.vic.gov.au/debatehistoric-voluntary-assisted-dying-bill-starts $>$

Department of Health and Human Services, Government of Victoria, 'Voluntary Assisted Dying: Overview', health.vic (Web Page) <https://www.health.vic. gov.au/patient-care/overview>

Standing Committee on Legal and Social Issues, Parliament of Victoria Legislative Council, 'Community Views Sought on Choices for End of Life' (Media Release, 28 May 2015) 
This text is taken from Voluntary Assisted Dying: Law? Health? Justice?, edited by Daniel J Fleming and David J Carter, published 2022 by ANU Press, The Australian National University, Canberra, Australia.

doi.org/10.22459/VAD.2022.01 